\title{
The Impact of Anti-Corruption on the Environmental Kuznets Curve: The Case of China
}

\author{
Donghao Duan, Nengsheng Luo* \\ School of Economics and Trade, Hunan University, Changsha 410006, China \\ Received: 14 December 2020 \\ Accepted: 13 April 2021
}

\begin{abstract}
This study makes an empirical test of the impact of anti-corruption on the relationship between economic growth and the environment and its spillover effects based on the balanced panel data of 31 provinces and cities in China from 2006 to 2017. Moreover, this study puts anti-corruption factors into the framework of the new Environmental Kuznets Curve (EKC) model using the panel model and spatial Durbin model. The following are the findings of this study. (1) EKC in China presents an inverted ' $\mathrm{N}$ ' shape with spillover effects between regions. (2) To a certain extent, anti-corruption can affect the turning point and shape of the EKC by optimising economic growth and curbing environmental pollution. (3) Anti-corruption within the region will impact the EKC outside the region, but the spillover effect is lower than the internal effect. (4) Time differences exist in EKC. The post-18th National Congress of the Communist Party of China significantly presents an inverted $\mathrm{N}$ curve that is different from the pre-18th National Congress condition. Besides, anti-corruption has significantly reduced the inflexion point of the relationship between economic growth and environmental pollution. Hence, anticorruption can maintain economic growth to a certain extent while restraining environmental pollution. China shall continue to firmly promote the process of anti-corruption to ensure sustainable economic and environmental development.
\end{abstract}

Keywords: anti-corruption, Environmental Kuznets Curve, spatial Durbin model, instrumental variables

\section{Introduction}

Since the Reform and Opening-up, China has become the world's second-largest economy at a rate that shocked all countries. However, the worsening of environmental pollution followed. The relationship between economy and environment has become a huge challenge in China's development, and it has also

*e-mail: lns1122@163.com attracted widespread and continuous attention from the academic community. Scholars used the Environmental Kuznets Curve (EKC) hypothesis to study the evolution of the relationship between China's economic development and the environment. They found that the conclusion does not support the inverted U-shaped EKC hypothesis. There exists a linear U-shaped and curve relationships such as $\mathrm{N}$ type and inverted $\mathrm{N}$ type [1]. Simultaneously, with China's reform and opening up and rapid economic development, corruption has become increasingly serious. Corruption not only 
erodes the foundation of economic development but also is an important cause of environmental pollution. Anti-corruption is imperative. The Chinese government continues to promote reform and opening up for economic development, while gradually increasing its anti-corruption efforts. Especially after the 18th National Congress of the Communist Party of China, China has launched a protracted anti-corruption struggle with unprecedented scale, intensity and influence, and official corruption has been significantly curbed.

Anti-corruption not only optimises the political ecology but also significantly impacts economic growth and environmental quality. At present, there is relevant literature on China's anti-corruption and economic growth, and the impact of anti-corruption on environmental pollution. For example, some studies believed that anti-corruption will restrain China's economic growth in the short term and promote economic growth in the long term [2]. They also believed that anti-corruption will reduce the level of environmental pollution and may improve the efficiency of environmental governance, etc. [3, 4]. However, a comprehensive research on the relationship between anti-corruption on economic growth and environmental pollution is lacking. In fact, anti-corruption will affect economic growth and environmental pollution simultaneously, and the effects are intertwined and interact with each other. Therefore, the three studies conducted must be combined to thoroughly explore the impact of anti-corruption on the environmental effect of economic growth. From an academic perspective, the impact of anti-corruption on the EKC has been explored. Based on this, this paper intends to discuss and answer the following question in depth: What is the shape of China's EKC? Did anti-corruption policies change the shape of this curve and optimise the relationship between economic growth and the environment? How does anti-corruption affect the relationship between China's economic growth and environmental pollution? The clarification of the above -mentioned problems has important reference significance for the resolution of national governance, economic construction and sustainable development.

Compared with previous studies, this paper has the following main contributions: (1) For the first time, the spatial Durbin model of different weight matrices has been used to test the spatial spillover effects of anti-corruption, economic growth and environmental pollution and to fill the research gap. (2) The previous literature mainly focused on the quadratic form of the environmental Kuznets hypothesis, whereas this present study is dedicated to testing the cubic form of the EKC. Moreover, we concluded that China's EKC presents an inverted $\mathrm{N}$, which has enriched the research in this direction. (3) Up to now, no literature puts China's anticorruption and EKC under the same overall framework for research. Therefore, this paper focuses on anticorruption and analyses the two from both theoretical and empirical aspects. Only in this way can we better explain the coexistence of strong anti-corruption and high economic growth in China. Moreover, this method can provide references for China's rapid economic growth and sustainable environmental development during the transition period.

The rest of this paper is arranged as follows. Section 2 reviews relevant literature. Section 3 presents the theoretical mechanism. Section 4 outlines the empirical model and introduces the variables and data sets. Section 5 reports the empirical results, heterogeneity analysis and robustness test. Section 6 summarises the full text and policy recommendations.

\section{Literature Review}

Corruption and anti-corruption are closely related; issues of the former appear earlier than those of the latter. To obtain a thorough understanding of the impact of anti-corruption on environmental pollution, we must understand the research on corruption issues. Since the end of the 20th century, research on corruption and environmental pollution at home and abroad have been conducted, mainly from the following aspects. Firstly, by putting corruption, economic growth and environmental pollution in the same frame, we found that corruption can deepen environmental pollution through the indirect impact on income [5-7]. Secondly, by analysing the relationship between corruption and environmental control, we found that corruption can deepen environmental pollution by reducing the effect of environmental regulation [8-11]. Thirdly, with the rapid development of economic globalisation, part of the studies on corruption's impact on the environment under open conditions have confirmed the impact of corruption on trade and foreign direct investment [12-14]. Fourthly, from the perspective of irregular economy, Biswas et al. and Yu explored the mechanism between corruption, irregular economy and environmental pollution [15, 16]. The hypothesis that the irregular economy has a significant impact on the environmental quality of a country is tenable; the higher the degree of corruption, the greater the negative impact of the informal economy on the environmental quality of a country.

The special national conditions of China's strong anti-corruption decision determine the insufficiency of studying corruption alone. Most research on anticorruption at home and abroad also focuses on China. From a macroperspective, $\mathrm{Nie}$ and $\mathrm{Li}$ studied the optimal anti-corruption policy of the government in different institutional environments and provided a theoretical guidance for China's anti-corruption policy and streamlining administration reform [17]. Wang et al. discussed the triangular relationship between corruption, anti-corruption and economic growth. They found that the degree of corruption will influence the effect of anti-corruption on economic growth. Moreover, they found that sustainable anti-corruption can reduce 
the overall corruption degree and realise sustainable economic development [18]. From the microperspective, Dang et al. found that anti-corruption increased the relevant cost of seeking political connections and that the innovation incentive of enterprises has been greatly improved [19]. Meanwhile, Zhong et al. provided empirical evidence for the implementation of anti-corruption and verified the hypothesis that corruption hindered economic development. Moreover, they pointed out that anti-corruption can improve enterprise performance [20]. Wang and Kong found that anti-corruption helps strengthen executive incentive mechanisms and improve company management and accounting quality to increase shareholder value [21]. Moreover, Wang et al. concluded that anti-corruption can significantly inhibit the scale of fixed asset investment from both theoretical and empirical aspects [22]. By introducing anti-corruption parameters into the classic principal-agent model, Yan and Qiao analysed the mechanism of anti-corruption on the executive's consumption and salary incentive effect during the executive's tenure of office [23]. Furthermore, some studies have explored the effect of anti-corruption on housing price [24].

The above literature focuses on the impact of anticorruption on the healthy development of the economy and society, streamlining administration, enterprise performance, and shareholder value. Besides, on the basis of clarifying the mechanism of anti-corruption on environmental pollution, Liu and Yang examined the impact of anti-corruption on environmental pollution and its interaction with environmental regulation. They found that the interaction between anti-corruption and environmental control presents an inverted $U$ curve relationship with environmental pollution. That is, to a certain degree, limited anti-corruption will increase environmental pollution, whereas sustained anticorruption with high intensity is beneficial to improve environment quality [3]. Simultaneously, Zhou et al. found that the pollution reduction effect of the anticorruption campaign could be achieved partially through the increased intensity of environmental regulations and economic development [4]. This paper will put anti-corruption, economic growth and environmental pollution under the same framework, conduct joint inspection by using the panel model and spatial Durbin model, and explore the influential mechanism of anticorruption on EKC.

Investigating the impact of local economic growth on environmental pollution has limitations. The huge spatial spillover effects of economic growth itself may spread to nearby or further areas. The ordinary least squares (OLS) method can only consider the influence of internal variables; it is difficult to expand to nearby areas. Therefore, it can make up for the common model setting error and obtain a more realistic and comprehensive estimation result based on the maximum likelihood (ML). At present, China is undergoing the intersection of history, with the deepening and development of anti-corruption progress, the relationship between economic growth and environmental pollution is apparently out-of-balance. Under this background, by using proper model, the overall research on the relationship between economic growth and environmental pollution is beneficial to deepen the understanding of EKC and correctly understand the relationship between economic growth and environmental pollution. Moreover, this study is helpful to strengthen China's belief in anti-corruption, implement the important concept of coordinated development under the new normal and promote the sustained and healthy development of China's economy.

\section{Theoretical Mechanism}

Anti-corruption is an important driving force for economic growth. It has a significant positive impact on both economic and investment growth. Anti-corruption methods and channels to improve economic growth include increasing investment levels and foreign direct investment, improving the efficiency of foreign aid, streamlining the public sector, optimising the structure of government fiscal expenditures and improving the efficiency of public investment allocation. Corruption will optimise the allocation of human capital, improve social and political stability, increase the incentives for people to engage in productive activities, strengthen the protection of property rights and encourage commercial activities, technological progress and transfer. Anticorruption has accelerated the expansion of enterprises, adopted high-tech, shifted their activities to formal departments and improved corporate efficiency. Moreover, anti-corruption can reduce the 'rent-seeking' space of power and detect illegal income and wealth from the system and reduce the waste of resources. After the 18th National Congress of the Communist Party of China, the anti-corruption campaign formed a high-pressure situation. Such high-pressure anticorruption action forms a new steady-state equilibrium between non-corruption from officials and economic growth, thereby ensuring stable economic growth.

With the normalisation of anti-corruption, the everincreasing efforts of anti-corruption have sent clearer policy signals. While forming a deterrent to corrupt officials, various market entities have gradually formed more stable policy expectations, and then, the behaviour of officials and polluting companies constituted hard constraints. Thus, the positive guiding role of anticorruption began to emerge. With the expansion of the scope of anti-corruption, the government's investment for treating environmental pollution and the actual implementation efforts have increased. Moreover, the number of companies that violate the regulations has been shut down, and the discharge of major pollutants has decreased. Entrepreneurs who have accepted the policy signals and gradually became accustomed to changes in environmental policy orientation set to 
reposition their relationship with government officials and coordinate their positions on pollution control with the government. Furthermore, they increase investment in pollution control and green technology innovation, thereby helping promote cleaner production and pollution reduction from the bottom up [3].

The formation of the EKC is mainly attributed to the scale, structural and technological effects. The scale effect refers to the expansion of economic scale based on resource consumption and environmental damage. The structural effect denotes a certain effect of the industrial structure's optimisation and upgrading on the environment. Meanwhile, the technical effect means that technological progress is conducive to improving energy efficiency [25]. This study conjectures that for developing countries, in the early stages of economic development, the foundation of light and heavy industries is weak, and pollution emissions are not serious. Moreover, in the middle of economic development, scale and structural effects play a leading role in the influence of the EKC, and both effects will exacerbate the deterioration of environmental quality. Finally, when the process of social industrialisation is completed, the industrial structure will change from a high-polluting, high-emission industry to a service industry due to industrial transfer and upgrading. At this time, structural and technological effects will gradually dominate, and pollution levels will decline. The continuous decline has formed the falling stage on the far-right side of the EKC; that is, the curve of the impact of China's economic growth on environmental pollution shows a trend of the first decline, then a rise, and finally a decline. On the one hand, anti-corruption can directly affect the EKC. On the other hand, it has an indirect impact on EKC through scale, structural and technological effects.

At present, most of the studies on the effect of economic growth on environmental pollution are focused on the conditions within a region and assumed no spatial spillover effect between economic growth and environmental pollution, which is obviously inconsistent with the facts. Besides, a spatial spillover effect on anti-corruption also exists. Anti-corruption action has no geographical or administrative boundaries; that is, it will not only significantly affect the same region but also spread to or gradually diffuse to remote areas.

\section{Material and Methods}

When analysing EKC, most scholars would take pollutant emission as the dependent variable, and per capita GDP and its square term and cubic term as the core variables to conduct linear regression analysis [26]. However, as Wagner mentioned, if the per capita GDP and its square term are combined, the regression equation includes the nonlinear transformation of these two variables. This regression method that includes the nonlinear transformation of the explanatory variable applies only to time-series data; it cannot be extended to the panel data model [27]. The model with per capita GDP and its square term fails to flexibly capture the extreme value of pollution emission at a certain level of economic growth. However, with the improvement of economic growth, there is a turning point in pollution emissions once again. By referring to Bradford et al., this paper pays attention to the investigation of EKC with the cubic term and sets a mathematical equation with double inflexion points based on this theory [28].

$$
p_{t}=\int_{0}^{y_{t}} \alpha\left(y_{t}-y^{*}\right)\left(y_{t}-y^{* *}\right) g_{t} d y_{t}
$$

In formula (1), $p_{t}$ refers to the dependent variable, expressed with $\mathrm{SO}_{2}$ emissions in the $t$ year; $\mathrm{y}_{\mathrm{t}}$ refers to the core variable, expressed with per capita GDP in the $t$ year; $g_{t}$ refers to per capita GDP growth rate; $y^{*}$ and $y^{* *}$ refer to the value of per capita GDP of EKC inflexion point; and $\alpha$ refers to an arbitrary constant.

To study the impact of anti-corruption on environmental pollution, this paper deepens the model of Bradford et al. [28]. Following previous studies by domestic and foreign scholars on the inflexion point of EKC and the degree of corruption, this paper verifies the degree of corruption affecting the value of inflexion point and the linear relationship between $\mathrm{y}^{*}$ and corruption degree. Thus, in this paper, the inflexion points $\mathrm{y}^{*}$ and $\mathrm{y}^{* *}$ of EKC are the equations about the strength of anti-corruption:

$$
\begin{aligned}
& y^{*}=\theta_{1} A_{t}+\theta_{2} \\
& y^{* *}=y^{*}+\theta_{3}
\end{aligned}
$$

In formula (2), $A_{t}$ is the anti-corruption degree of different provinces and cities. $\theta_{1}, \theta_{2}$ and $\theta_{3}$ refer to absolute terms. The EKC equation (4), including the cubic term of real per capita GDP, can be obtained by combining formulas (1), (2) and (3).

$$
\left.p_{t}=\int_{0}^{y_{t}} \alpha\left[y_{t}-\left(\theta_{1} A_{t}+\theta_{2}\right)\right] y_{t}-\left(\theta_{1} A_{t}+\theta_{2}+\theta_{3}\right)\right] g_{t} d y_{t}
$$

Based on equation (4), equation (5) is obtained by performing an integral operation with consideration of the provincial fixed effect $\left(\mu_{i}\right)$, period fixed effect $\left(v_{t}\right)$, random disturbance $\left(\varepsilon_{i t}\right)$, and other control variables $\left(C_{i t}\right)$ affecting environmental pollution emission.

$$
\begin{aligned}
p_{i t} & =\beta_{0}+\beta_{1} g_{i t} y_{i t}{ }^{3}+\beta_{2} A_{i t} g_{i t} y_{i t}{ }^{2}+\beta_{3} g_{i t} y_{i t}{ }^{2}+\beta_{4} A_{i t}{ }^{2} g_{i t} y_{i t} \\
& +\beta_{5} A_{i t} g_{i t} y_{i t}+\beta_{6} g_{i t} y_{i t}+\beta_{7} C_{i t}+\mu_{i}+v_{t}+\varepsilon_{i t}
\end{aligned}
$$




\section{Variables and Data}

\section{Core Variable}

Pollution emission (p): This study draws on the practice of Ouyang et al. and uses per capita industrial sulphur dioxide $\left(\mathrm{SO}_{2}\right)$ emissions as the explained variable in the text [29]. As an important part of air pollution, $\mathrm{SO}_{2}$ has an obvious diffusion and agglomeration effects in time and space that can better be used to fit spatial econometric model. Meanwhile, to comprehensively measure environmental pollution, the sum of per capita industrial solid waste and per capita chemical oxygen demand in industrial wastewater will be selected to test as dependent variables. The data of pollution emissions are from the China Statistical Yearbook and the official websites of statistical bureaus of various provinces and cities.Anti-corruption efforts (A): Anti-corruption has two measurement methods: direct and indirect.

(1) Direct measurement. As Wang et al. demonstrated, the number of corruptions, bribery and dereliction of duty in provincial procuratorial organs cannot be used as the proxy variable of corruption or anti-corruption in detail from a multidimensional perspective. In fact, the number of 'cases on file' integrates the common functions of corruption and anticorruption [18]. Referring to this viewpoint, we searched for the number of articles with the keyword 'corruption' in the local organ newspapers every year and divided it by the number of articles in the newspaper with the keyword 'government' in the same year. We regarded it as the index to measure anti-corruption efforts in each province. The data are from CNKI Chinese Crucial Newspapers Full-text Database.

(2) Indirect measurement. Since the opening of the 18th CPC National Congress in 2012 and the reselection of the leading group of the central government, anti-corruption efforts have been strengthened. On this basis, taking 2012 as the time node of policy shock, we denote the period before 2012 as $\mathrm{A}=0$, and $\mathrm{A}=1$, otherwise [30]. The data are obtained from the official website of the Central Commission for Discipline Inspection. The explained variable of re-selection of the central government's leading group will be included in the robustness test to examine the robustness of regression results.

Real GDP per capita (y): The per capital nominal GDP fails to confirm the real GDP level; hence, this paper draws on the practise of $\mathrm{Yu}$ and uses 2006 as the base period and the GDP deflator to reduce the regional data. Besides, to reduce the multi-collinearity problem, this paper standardises the index to make it tally with the characteristics of normal distribution [16]. The data are obtained from the China Statistical Yearbook and the official websites of statistical bureaus of various provinces and cities.

Real GDP per capita growth rate (g): based on the real GDP per capita 2005 data obtained by the GDP deflator, we can calculate the real GDP per capita growth rate from 2006 to 2017 [26]. The data source is the same as the above.

\section{Control Variable}

Cole (2007), Leitao (2010), Yu (2019) and Liu (2020) showed that industrial structure changes (manu), trade openness (open), R\&D intensity (rd) and energy consumption (eng) disturbance factors related to population, economic structure, energy, foreign trade, technology and environmental regulations, such as the rate of change (ur), population density (pd) and environmental regulation intensity (er), are controlled by empirical norms $[3,6,7,16]$. Industrial structure change (manu) is expressed by the ratio of industrial value-added of each region to GDP. Trade openness (open) is expressed by the ratio of the total import and export of each region to GDP. Meanwhile, R\&D intensity ( $\mathrm{rd}$ ) is expressed by the ratio of internal expenditure of $\mathrm{R} \& \mathrm{D}$ funds of each region to GDP. Urbanisation rate (ur) is expressed by the ratio of the urban population in a province to the whole population. Population density (pd) is expressed as the ratio of the total population of each province to the land area. Energy consumption (eng) is expressed by the ratio of energy consumption in different provinces to GDP. The intensity of environmental regulation (er) is expressed by the ratio of pollution levy fee of key industrial enterprises in different regions (pwf) to industrial added value. The data about the above control variables are obtained from the China Statistical Yearbook, China Science and Technology Statistical Yearbook, China Energy Statistical Yearbook, and China Environment Yearbook.

The sample data are from the panel data of 31 provinces (excluding Hong Kong, Macao and Taiwan) in China from 2006 to 2017. To ensure the balance of panel data, this paper supplements some missing data by using a linear interpolation method and average growth-rate-filling method. The descriptive statistical results of the main variables are shown in Table 1.

\section{Spatial Measurement Model Setting}

Equation (5) only considers EKC but fails to comprehensively investigate its spatial correlation. Hence, the spatial econometric model also needs to be studied. At present, the common spatial econometric models include the spatial autoregressive model (SAR), spatial error model (SEM) and spatial Durbin model (SDM). Among them, SAR is usually used to investigate the spatial dependence of a region's explained variable on that in other regions; SEM is often used to observe the spatial connection between uncontrollable factors and missing variables; SDM is more general and considers the lag terms of explanatory variables and explained variables. 
Table 1. Descriptive statistics of main variables.

\begin{tabular}{|c|c|c|c|c|c|}
\hline Variable names & Sample size & Mean & Variance & Min & Max \\
\hline Pollution emission & 372 & 0.015 & 0.011 & 0.0002 & 0.061 \\
\hline Anti-corruption & 372 & 0.097 & 0.067 & 0.008 & 0.514 \\
\hline Real GDP per capital & 372 & 35864.99 & 25629.98 & 5750 & 153000 \\
\hline GDP growth rate & 372 & 0.108 & 0.03 & -0.025 & 0.192 \\
\hline Industrial structure & 372 & 0.384 & 0.099 & 0.068 & 0.53 \\
\hline Trade openness & 372 & 0.302 & 0.369 & 0.017 & 1.721 \\
\hline R \& D & 372 & 0.003 & 0.005 & 0.0003 & 0.031 \\
\hline Urbanization rate & 372 & 0.526 & 0.145 & 0.211 & 0.896 \\
\hline Population density & 372 & 0.044 & 0.065 & 0.0003 & 0.383 \\
\hline Energy consumption & 372 & 1.392 & 2.264 & 0.255 & 19.057 \\
\hline Environmental regulation & 372 & 0.001 & 0.001 & 0.001 & 0.009 \\
\hline Instrumental variable & 372 & 4.309 & 2.076 & 0.864 & 11.456 \\
\hline
\end{tabular}

Referring to the examination thought of Elhorst, we tested LM and LM-Robust to ensure the existence of spatial dependence. Then, LR and Wald tests are conducted to determine the final model selection. According to the statistical test (i.e. SLM, SEM, or both are suitable), if OLS is refused, then an SDM shall be taken for the estimation instead of selecting directly [31]. If the LR and Wald tests all pass the established significance level test and strongly overturn the original hypothesis, the optimal model would be SDM. The test results of spatial dependence diagnosis is shown in Table 2.

Results reveal that the test values of $\mathrm{LM}_{\text {lag }}$-Robust and $\mathrm{LM}_{\text {lag }}$ are insignificant and significant at the 5\% level, respectively. Meanwhile, the other test values of LM are significant at the $1 \%$ level, implying that the optimal spatial econometric model cannot be determined. Therefore, this paper conducts further tests of LR and Wald and finds that the test values are

Table 2. The test results of spatial dependence diagnosis.

\begin{tabular}{|c|c|}
\hline Test statistics & Statistics \\
\hline $\mathrm{LM}_{\text {lag }}$ & $5.636 * *(0.018)$ \\
\hline $\mathrm{LM}_{\text {lag }}-$ Robust & $2.414(0.120)$ \\
\hline $\mathrm{LM}_{\text {error }}$ & $21.610 * * *(0.000)$ \\
\hline $\mathrm{LM}_{\text {error }}$-Robust & $18.388 * * *(0.000)$ \\
\hline $\mathrm{LR}_{\mathrm{lag}}$ & $25.11 * * *(0.000)$ \\
\hline $\mathrm{LR}_{\text {error }}$ & $26.66 * * *(0.000)$ \\
\hline \multirow{2}{*}{$\begin{array}{l}\text { Spatial fixed effects } L R_{\text {test }} \\
\text { Time fixed effect } L R_{\text {test }}\end{array}$} & $169.62 * * *(0.000)$ \\
\hline & $543.04 * * *(0.000)$ \\
\hline Wald $_{\text {lag }}$ & $25.85 * * *(0.000)$ \\
\hline Wald $_{\text {error }}$ & $28.47 * * *(0.000)$ \\
\hline
\end{tabular}

significant at the $1 \%$ level. SDM cannot return to SLM or SEM; the data can be fit better by selecting SDM. Simultaneously, according to the joint significance test results, a significant two-way fixed effect of time and space exists in the model. SDM in both time and space must be fixed to make the estimated results more effective. The SDM set in this paper is as follows:

$$
\begin{gathered}
p_{i t}=\alpha_{0}+\lambda_{0} W \cdot p_{i t}+\lambda_{1} W \cdot g_{i t} y_{i t^{3}}+\lambda_{2} W \cdot A_{i t} g_{i t} y_{i t}{ }^{2} \\
+\alpha_{1} g_{i t} y_{i t}{ }^{3}+\alpha_{2} A_{i t} g_{i t} y_{i t}{ }^{2}+\alpha_{2} g_{i t} y_{i t}{ }^{2}+\alpha_{3} A_{i t}{ }^{2} g_{i t} y_{i t} \\
+\alpha_{4} A_{i t} g_{i t} y_{i t}+\alpha_{5} g_{i t} y_{i t}+\alpha_{6} C_{i t}+\mu_{i}+v_{t}+\varepsilon_{i t}
\end{gathered}
$$

Among it, $\lambda_{0}$ refers to the spatial correlation coefficient vector. If the spatial correlation is positive, then $\lambda_{0}>0$; otherwise, $\lambda_{0}<0$. W refers to different spatial weight matrices. Other variables are the same as equation (5).

The spatial weight matrix can be set in the following three common methods:

(1) Distance economic weight matrix: $\mathrm{W}_{1}=1 /\left|\mathrm{Y}_{\mathrm{i}}-\mathrm{Y}_{\mathrm{j}}\right|$ $(i \neq j), W_{1}=0(i=j)$. In this matrix, $Y$ refers to per capita GDP of each region obtained by GDP deflator with 2006 as the base period. The economic gap is inversely proportional to economic weight.

(2) Geographic adjacency weight matrix. Suppose the two places are close to each other geographically, then $\mathrm{W}_{2}=1(\mathrm{i} \neq \mathrm{j})$; otherwise, $\mathrm{W}_{2}=0(\mathrm{i}=\mathrm{j})$.

(3) Geographic distance weight matrix: $W_{3}=1 / d_{i j}$ $(i \neq j), W_{3}=0(i=j)$. In this matrix, $d_{i j}$ refers to the linear distance of provincial capitals that is accurate to the longitude and latitude of each city centre. Geographic distance is inversely proportional to geographic weight.

This paper considers using three weight matrices to estimate spatial Durbin model and analyses the EKC spatial spillover effect in different weight matrix. 
Simultaneously, this paper tests the robustness of the econometric model.

\section{Results and Discussion}

Here, we conduct a panel model regression of equation (5). This method can not only test the effect of EKC in a province but also lay the groundwork and compare the regression of equation (6) with spatial Durbin model.

\section{Panel Model Regression}

Through the correlation coefficient analysis, $\ln \left(\mathrm{gy}^{3}\right)$, $\ln \left(\mathrm{Agy}^{2}\right), \ln \left(\mathrm{gy}^{2}\right), \ln \left(\mathrm{A}^{2} \mathrm{gy}\right), \ln (\mathrm{Agy})$ and $\ln (\mathrm{gy})$ are found to be highly correlated. The result of the VIF test (Mean VIF $=22.10)$ demonstrate the multicollinearity of the regression equation. Further research found that the coefficients of the explanatory variables changed accordingly through forward and reverse stepwise regression and that the regression fails to achieve the 'optimal' result. On this basis, multicollinearity among the main explanatory variables can be inferred to affect the robustness of the regression results. Moreover, according to Dong et al., controlling more variables will consume too many degrees of freedom [32]. The cubic EKC Hypothesis must only test the inflexion point level and the curve shape. Hence, taking $\ln \left(\mathrm{Agy}^{2}\right)$ and $\ln \left(A^{2} g y\right)$ as core variables is enough for empirical research ${ }^{1}$. By observing the plot of residuals and white test $\left(\chi^{2}(44)=74.42\right)$, we found heteroscedasticity in empirical data. To solve this problem, we should set up a robust standard deviation or clustering robust standard deviation for regression equation. 'Panel random effect + clustering robust standard deviation' model (RE-Robust) and Generalised Least Square method (GLS) can eliminate the heteroscedasticity to the greatest extent that is suitable for our requirement [33].

There may be an opposite causal relationship between anti-corruption and environmental pollution, that are, provinces with serious environmental pollution are more likely to improve the intensity of environmental control to reduce the occurrence of environmental corruption. Simultaneously, it might be an omitted variable bias existing in equation setting, that is, some factors will affect anti-corruption and environmental pollution. Hence, to solve possible endogenous problems, data availability needs to be taken into consideration. This paper takes average wages of public administration, social security, and social organisations (IV) in different provinces from 2005 to 2016 as the tool variable of

To ensure the balance of panel data, before taking the logarithm, the two indexes of $\mathrm{Agy}^{2}$ and $\mathrm{A}^{2} \mathrm{gy}$ are standardised to the interval of $[0,1]$. The formula is as follows: $\mathrm{S} /\{\mathrm{Max}$ (S)-Min $(\mathrm{S})\} \times 0.4+0.6$, where $\mathrm{S}$ is the index to be processed. anti-corruption ${ }^{2}$, mainly for the following reasons. IV is closely related to anti-corruption. To some extent, it can represent the economic situation and salary level of public officials. Some scholars have pointed out that improve the salary level of public officials enables to reduce corruption phenomenon to a certain extent [34]. Simultaneously, the average wage level has no direct relationship with environmental pollution, and the wage level can only affect environmental pollution through anti-corruption efforts.

The GMM model is more efficient than the 2SLS model in the case of tool variables and heteroscedasticity. When doing 2SLS regression, this paper reports the estimated result of GMM model for improving the accuracy of results. Before regression with instrumental variables, validity test and endogeneity test of tool variables shall be conducted. The paper lists the test results of the 2SLS model but will not discuss the GMM regression process in detail for the length limitations. Firstly, when conducting heteroscedasticity robust DWH test, $\mathrm{P}=0.0021$. therefore, $\ln \left(\mathrm{A}^{2} \mathrm{gy}\right)$ is an endogenous variable. Then, the relationship between the tool and endogenous variables is tested. In the first phase, $F=62.8633(P=0.0000)$, Shea's $R^{2}=0.3526$. Thus, instrumental variables are strongly correlated with endogenous variables, eliminating the hidden danger of weak instrumental variables. Finally, this paper omits the test for a single tool variable cannot do over identification testing.

In: improve the accuracy of estimation, regression results of OLS and MLE are shown in Table 3. It can be seen that, the coefficient $\beta_{2}$ of $\ln \left(\mathrm{Agy}^{2}\right)$ is significantly negative, the coefficient $\beta_{4}$ of $\ln \left(\mathrm{A}^{2} \mathrm{gy}\right)$ is significantly positive. That is, $\alpha<0, \theta_{1}>0$. It means EKC in a province presents an inverted $\mathrm{N}$ curve. To a certain extent, anti-corruption can reduce environmental pollution. The greater the anti-corruption efforts, the lower the economic growth level corresponding to the inflexion point.

Simultaneously, in Table 3, the change in industrial structure, urbanisation rate, and energy consumption are significantly positive that shows these control variables aggravate environmental pollution. Besides, the regression results of columns (2) - (6) in Table 3 are consistent with those in column (1). It elaborates that multicollinearity, heteroscedasticity, and endogeneity do not significantly affect the robustness of the regression results.

\section{Regression of Spatial Econometric Model}

\section{Spatial Dependence}

As negative externalities in the process of economic growth, environmental pollution will produce spatial transfer and diffusion of pollutants with the change

2 The data is from China Statistical Yearbook. 
Table 3. Regression results of Panel model.

\begin{tabular}{|c|c|c|c|c|c|c|}
\hline & (1) & (2) & (3) & (4) & (5) & (6) \\
\hline & OLS & RE ROBUST & GLS & MLE & IV-2SLS ROBUST & IV-GMM \\
\hline $\ln \left(\mathrm{Agy}^{2}\right)$ & $\begin{array}{c}-7.060 * * * \\
(-4.43)\end{array}$ & $\begin{array}{c}-6.467 * * * \\
(-3.26)\end{array}$ & $\begin{array}{c}-5.107 * * * \\
(-3.76)\end{array}$ & $\begin{array}{c}-6.192 * * * \\
(-4.60)\end{array}$ & $\begin{array}{c}-15.11 * * * \\
(-4.29)\end{array}$ & $\begin{array}{c}-15.11 * * * \\
(-4.29)\end{array}$ \\
\hline \multirow[t]{2}{*}{$\ln \left(\mathrm{A}^{2} \mathrm{gy}\right)$} & $6.444 * * *$ & $6.566 * * *$ & $5.914 * * *$ & $6.475 * * *$ & $15.92 * * *$ & $15.92 * * *$ \\
\hline & $(4.13)$ & $(4.44)$ & $(4.44)$ & $(5.61)$ & $(4.23)$ & $(4.23)$ \\
\hline \multirow[t]{2}{*}{ lnmanu } & $2.016 * * *$ & $1.810 * * *$ & $2.102 * * *$ & $1.524 * * *$ & $1.975 * * *$ & $1.975^{* * *}$ \\
\hline & $(22.80)$ & $(4.24)$ & (22.84) & $(8.78)$ & (16.58) & $(16.58)$ \\
\hline \multirow[t]{2}{*}{ lnopen } & -0.0676 & $-0.146^{*}$ & -0.0264 & $-0.154 * *$ & -0.0390 & -0.0390 \\
\hline & $(-1.56)$ & $(-1.84)$ & $(-0.81)$ & $(-2.50)$ & $(-0.91)$ & $(-0.91)$ \\
\hline \multirow[t]{2}{*}{$\operatorname{lnrd}$} & 0.0101 & -0.0766 & 0.00943 & $-0.129 *$ & 0.0463 & 0.0463 \\
\hline & $(0.31)$ & $(-0.94)$ & $(0.41)$ & $(-1.76)$ & $(1.41)$ & $(1.41)$ \\
\hline \multirow[t]{2}{*}{ lnur } & $1.020 * * *$ & $0.726^{* *}$ & $0.665^{* * *}$ & 0.541 & $1.205^{* * *}$ & $1.205^{* * *}$ \\
\hline & $(5.76)$ & $(2.24)$ & $(4.74)$ & $(1.62)$ & (6.64) & $(6.64)$ \\
\hline \multirow[t]{2}{*}{$\operatorname{lnpd}$} & -0.0402 & 0.166 & -0.0358 & $0.248 * * *$ & -0.0114 & -0.0114 \\
\hline & $(-1.18)$ & $(1.58)$ & $(-1.28)$ & $(2.86)$ & $(-0.32)$ & $(-0.32)$ \\
\hline \multirow[t]{2}{*}{ lneng } & $0.337 * * *$ & $0.970 * * *$ & $0.442 * * *$ & $1.107 * * *$ & $0.376 * * *$ & $0.376^{* * *}$ \\
\hline & $(3.97)$ & $(3.90)$ & $(5.66)$ & $(8.10)$ & $(3.29)$ & $(3.29)$ \\
\hline \multirow[t]{2}{*}{ lner } & $0.371 * * *$ & -0.116 & $0.362 * * *$ & $-0.216^{* * *}$ & $0.394 * * *$ & $0.394 * * *$ \\
\hline & $(6.16)$ & $(-0.87)$ & $(7.08)$ & $(-3.41)$ & $(4.90)$ & $(4.90)$ \\
\hline \multirow[t]{2}{*}{ _cons } & 0.246 & $-3.048^{* *}$ & 0.763 & $-4.105^{* * *}$ & $1.618^{*}$ & $1.618^{*}$ \\
\hline & $(0.36)$ & $(-2.56)$ & $(1.37)$ & $(-4.69)$ & $(1.79)$ & $(1.79)$ \\
\hline$N$ & 372 & 372 & 372 & 372 & 372 & 372 \\
\hline $\operatorname{adj} \cdot R^{2}$ & 0.716 & - & - & - & 0.687 & 0.687 \\
\hline
\end{tabular}

Notes: $* * *$ means $\mathrm{p}<0.01,{ }^{*}$ means $\mathrm{p}<0.05, *$ means $\mathrm{p}<0.1$.

of natural environment, that is, environmental pollution may have a correlation effect in space. Moreover, competition among regions may lead to the correlation in space. Industrial agglomeration in a certain area may affect the discharge of pollutants to surrounding areas.

Moran's I is used to study the spatial correlation of environmental pollution in this paper. The value range of Moran's $I$ is $[-1,1]$, which is used to judge whether there is auto-correlation in space. At the specified significance level, if the value of Moran's $I>0$, then there is a positive auto-correlation in space. If the value of Moran's $\mathrm{I}<0$, then there is a negative autocorrelation in space. Otherwise, there is no spatial correlation. As shown in Fig. 1, the Moran's I index of environmental pollution in China's provinces from 2006 to 2017 fluctuated between 0.099 and 0.143 and passed the significance level test of $10 \%$. It shows that environmental pollution in various provinces in China is positively spatial dependent.

Through Moran scatter plot, we can directly observe whether environmental pollution variables and their spatial lag vectors have spatial dependence. The Moran scatterplot of environmental pollution of each province in 2006 is shown in Fig. 2. It can be seen that there is a space correlation in environmental pollution of various provinces. The provinces with similar pollution levels are relatively concentrated and show an obvious spatial agglomeration effect in economic distance space. Global Moran's I and Moran scatterplot show that it is necessary to consider the spatial correlation.

\section{Estimation Results of Spatial Durbin Model}

Based on econometric model (6), corresponding quantitative regression results of Different spatial weight matrices are shown in Table 4. It can be found columns (1), (4) and (7) in that, the signs of the regression coefficients of the direct effects of the variables $\ln \left(\mathrm{Agy}^{2}\right)$ and $\ln \left(\mathrm{A}^{2} \mathrm{gy}\right)$ are consistent with the panel regression results, indicating that the regression results of this paper are relatively robust. In addition, it can be seen from the regression results in column (4) of 


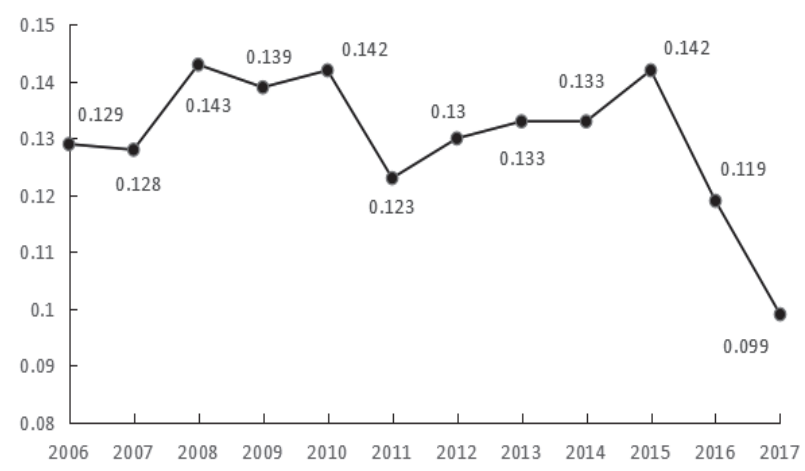

Fig. 1. Line chart of Moran's I of environmental pollution of each province over the years.

Table 4 that the coefficient $\lambda_{1}$ of $\mathrm{W} \cdot \ln \left(\mathrm{Agy}^{2}\right)$ is positive, and the coefficient $\lambda_{2}$ of $\mathrm{W} \cdot \ln \left(\mathrm{A}^{2} \mathrm{gy}\right)$ is negative, which means EKC among provinces presents an $\mathrm{N}$ curve. With the development of the economy, environmental pollution has experienced a process of first rising, then falling, and finally rising. To a certain extent, anticorruption within the region has reduced the level of environmental pollution in the region. By comparing with the regression coefficient of core variables in Table 3, the EKC is different in a region and among regions, that is, the spillover effect is lower than the internal effect, and there is a localisation phenomenon.

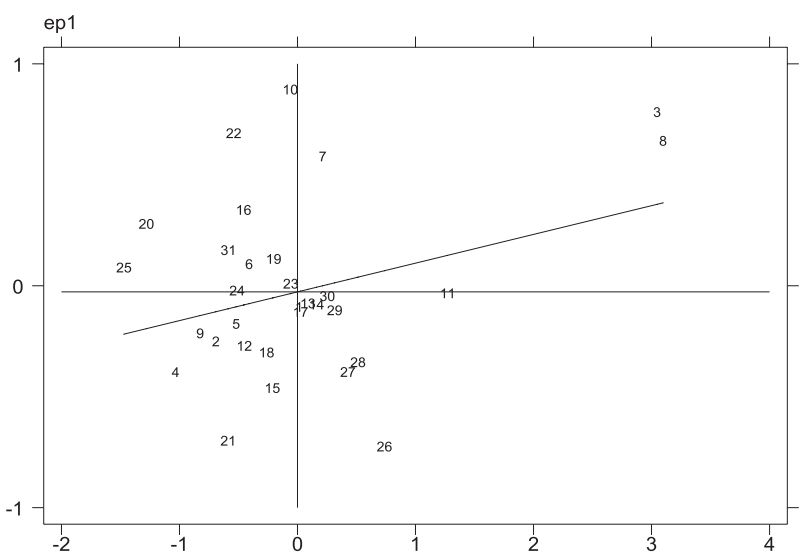

Fig. 2. The Moran scatter plot of environmental pollution of each province in 2006.

\section{Heterogeneity Analysis}

The regression results show that, on the whole, there is an inverted $\mathrm{N}$ EKC in different provinces, and anti-corruption reduces the inflexion point of economic growth. Are the above research results tenable in different periods of time? Because of this, taking 2012 as the time node of anti-corruption, this paper divides regression interval in to two parts, before and after the $18^{\text {th }}$ CPC National Congress. The test results are shown in Table 5 and Table 6.

Table 4. Regression results of spatial Durbin model.

\begin{tabular}{|c|c|c|c|c|c|c|c|c|c|}
\hline & \multicolumn{3}{|c|}{ Distance economic } & \multicolumn{3}{|c|}{ Geographic adjacency } & \multicolumn{3}{|c|}{ Geographic distance } \\
\hline & (1) & (2) & (3) & (4) & (5) & (6) & (7) & (8) & (9) \\
\hline $\ln \left(\mathrm{Agy}^{2}\right)$ & $-3.152 * * *$ & $-7.084 * * *$ & $-3.729 * * *$ & $-2.556 * *$ & $-6.841 * * *$ & $-3.608 * * *$ & $-2.858 * * *$ & $-7.125^{* * *}$ & $-4.175 * * *$ \\
\hline & $(-2.95)$ & $(-4.06)$ & $(-4.54)$ & $(-2.40)$ & $(-3.94)$ & $(-4.42)$ & $(-2.82)$ & $(-4.15)$ & $(-5.22)$ \\
\hline $\ln \left(\mathrm{A}^{2} \mathrm{gy}\right)$ & $3.161 * * *$ & $5.350 * * *$ & $2.231 * * *$ & $2.612 * * *$ & $5.111 * * *$ & $2.235 * * *$ & $2.935^{* * *}$ & $5.421 * * *$ & $3.013 * * *$ \\
\hline & $(3.28)$ & $(3.40)$ & $(2.72)$ & $(2.69)$ & $(3.24)$ & $(2.77)$ & $(3.16)$ & $(3.45)$ & $(3.69)$ \\
\hline lnmanu & $-0.414 * * *$ & $0.715 * * *$ & $-0.409 * *$ & $-0.432 * * *$ & $0.692 * * *$ & $-0.469 * * *$ & $-0.400 * * *$ & $0.712 * * *$ & $-0.417 * * *$ \\
\hline & $(-2.60)$ & $(2.75)$ & $(-2.57)$ & $(-2.73)$ & $(2.68)$ & $(-2.98)$ & $(-2.62)$ & $(2.75)$ & $(-2.80)$ \\
\hline lnopen & $-0.326^{* * *}$ & 0.00451 & $-0.340 * * *$ & $-0.333 * * *$ & 0.00276 & $-0.347 * * *$ & $-0.322 * * *$ & 0.000929 & $-0.317 * * *$ \\
\hline & $(-6.81)$ & $(0.06)$ & $(-7.25)$ & $(-7.02)$ & $(0.04)$ & $(-7.41)$ & $(-7.01)$ & $(0.01)$ & $(-7.05)$ \\
\hline $\operatorname{lnrd}$ & 0.00143 & -0.0616 & -0.00201 & 0.0173 & -0.0506 & 0.00982 & 0.0338 & -0.0745 & 0.0436 \\
\hline & $(0.02)$ & $(-0.62)$ & $(-0.03)$ & $(0.28)$ & $(-0.51)$ & $(0.16)$ & $(0.58)$ & $(-0.75)$ & $(0.78)$ \\
\hline lnur & $2.656^{* * *}$ & $1.996 * * *$ & $2.257 * * *$ & $2.683 * * *$ & $1.960 * * *$ & $2.261 * * *$ & $2.495^{* * *}$ & $1.880 * * *$ & $2.092 * * *$ \\
\hline & $(8.18)$ & $(3.76)$ & $(6.90)$ & $(8.42)$ & $(3.79)$ & $(7.02)$ & $(8.04)$ & $(3.60)$ & $(6.76)$ \\
\hline $\operatorname{lnpd}$ & -0.335 & 0.975 & 0.473 & -0.354 & 0.915 & 0.420 & -0.254 & 0.910 & 0.546 \\
\hline & $(-0.76)$ & $(1.36)$ & (1.05) & $(-0.80)$ & $(1.28)$ & $(0.92)$ & $(-0.60)$ & (1.27) & $(1.28)$ \\
\hline lneng & $0.398 * *$ & $1.491 * * *$ & $0.295^{*}$ & $0.464 * * *$ & $1.424 * * *$ & $0.363 * *$ & $0.348 * *$ & $1.458 * * *$ & 0.223 \\
\hline & $(2.32)$ & $(5.32)$ & $(1.76)$ & (2.69) & $(5.14)$ & $(2.17)$ & $(2.12)$ & $(5.28)$ & $(1.40)$ \\
\hline lner & $-0.103 * *$ & $0.176 * * *$ & $-0.0736^{*}$ & $-0.110 * * *$ & $0.165^{* *}$ & $-0.0772 *$ & $-0.110 * * *$ & $0.175 * * *$ & $-0.0701^{*}$ \\
\hline
\end{tabular}


Table 4. Continued.

\begin{tabular}{|c|c|c|c|c|c|c|c|c|c|}
\hline & $(-2.49)$ & $(2.63)$ & $(-1.77)$ & $(-2.73)$ & $(2.48)$ & $(-1.91)$ & $(-2.81)$ & $(2.65)$ & $(-1.82)$ \\
\hline $\mathrm{W} \cdot \ln \left(\mathrm{Agy}^{2}\right)$ & -0.640 & -0.0171 & -1.320 & $3.174 *$ & 0.0918 & 1.993 & 1.866 & -1.245 & $-9.661 *$ \\
\hline & $(-0.24)$ & $(-0.00)$ & $(-0.65)$ & $(1.88)$ & $(0.03)$ & $(1.36)$ & $(0.35)$ & $(-0.14)$ & $(-1.92)$ \\
\hline $\mathrm{W} \cdot \ln \left(\mathrm{A}^{2} \mathrm{gy}\right)$ & 0.566 & 1.606 & 0.849 & -2.471 & -0.296 & -1.275 & 0.245 & 1.949 & $13.09 * *$ \\
\hline & $(0.24)$ & $(0.42)$ & $(0.52)$ & $(-1.48)$ & $(-0.11)$ & $(-0.84)$ & $(0.04)$ & $(0.19)$ & $(2.21)$ \\
\hline rho & 0.0995 & -0.110 & 0.0818 & 0.0239 & $-0.166 *$ & 0.0632 & $-0.871 * * *$ & -0.268 & $-0.947 * * *$ \\
\hline & $(1.39)$ & $(-1.24)$ & $(1.07)$ & $(0.32)$ & $(-1.88)$ & $(0.82)$ & $(-3.89)$ & $(-1.12)$ & $(-4.00)$ \\
\hline sigma2_e & $0.0406 * * *$ & $0.108 * * *$ & $0.0384 * * *$ & $0.0405 * * *$ & $0.107 * * *$ & $0.0382 * * *$ & $0.0377 * * *$ & $0.108 * * *$ & $0.0350^{* * *}$ \\
\hline & $(13.61)$ & $(13.61)$ & $(13.62)$ & $(13.64)$ & $(13.58)$ & $(13.63)$ & $(13.44)$ & $(13.60)$ & $(13.35)$ \\
\hline Fixed time & YES & YES & YES & YES & YES & YES & YES & YES & YES \\
\hline Fixed ind & YES & YES & YES & YES & YES & YES & YES & YES & YES \\
\hline$N$ & 372 & 372 & 372 & 372 & 372 & 372 & 372 & 372 & 372 \\
\hline
\end{tabular}

Notes: $* * *$ means $\mathrm{p}<0.01, * *$ means $\mathrm{p}<0.05, *$ means $\mathrm{p}<0.1$.

Table 5. Panel model regression results before the $18^{\text {th }}$ CPC National Congress.

\begin{tabular}{|c|c|c|c|c|c|c|}
\hline & (1) & (2) & (3) & (4) & (5) & (6) \\
\hline & OLS & RE ROBUST & GLS & MLE & IV-2SLS ROBUST & IV-GMM \\
\hline \multirow[t]{2}{*}{$\ln \left(\mathrm{Agy}^{2}\right)$} & $10.11 * * *$ & -1.256 & $6.974 * * *$ & -2.060 & $5.483 *$ & $5.483^{*}$ \\
\hline & (3.19) & $(-1.10)$ & $(3.44)$ & $(-1.34)$ & $(1.74)$ & $(1.74)$ \\
\hline \multirow[t]{2}{*}{$\ln \left(\mathrm{A}^{2} \mathrm{gy}\right)$} & $-14.06 * * *$ & $4.466^{*}$ & $-8.858 * * *$ & $5.934 * *$ & -3.348 & -3.348 \\
\hline & $(-2.65)$ & (1.94) & $(-3.00)$ & $(2.47)$ & $(-0.59)$ & $(-0.59)$ \\
\hline \multirow[t]{2}{*}{ lnmanu } & $1.780 * * *$ & $0.788 * *$ & $1.772 * * *$ & 0.250 & $1.767 * * *$ & $1.767 * * *$ \\
\hline & $(17.56)$ & $(2.43)$ & (18.68) & $(1.44)$ & (14.77) & (14.77) \\
\hline \multirow[t]{2}{*}{ lnopen } & $-0.187 * * *$ & -0.0186 & $-0.125 * * *$ & 0.0339 & $-0.181 * * *$ & $-0.181 * * *$ \\
\hline & $(-4.59)$ & $(-0.38)$ & $(-5.19)$ & $(0.85)$ & $(-5.07)$ & $(-5.07)$ \\
\hline \multirow[t]{2}{*}{$\ln r d$} & 0.00445 & $-0.127^{*}$ & $0.0441 * * *$ & $-0.151 * * *$ & 0.0172 & 0.0172 \\
\hline & $(0.15)$ & $(-1.77)$ & (2.99) & $(-3.40)$ & $(0.62)$ & $(0.62)$ \\
\hline \multirow[t]{2}{*}{ lnur } & $1.110 * * *$ & $0.577^{*}$ & $0.957 * * *$ & $0.655^{* *}$ & $1.122 * * *$ & $1.122 * * *$ \\
\hline & $(6.49)$ & $(1.74)$ & $(8.73)$ & $(2.30)$ & (6.11) & (6.11) \\
\hline \multirow[t]{2}{*}{$\operatorname{lnpd}$} & $-0.108 * * *$ & 0.0638 & $-0.105 * * *$ & 0.0916 & $-0.102 * * *$ & $-0.102 * * *$ \\
\hline & $(-3.60)$ & $(0.53)$ & $(-5.47)$ & (0.99) & $(-3.76)$ & $(-3.76)$ \\
\hline \multirow[t]{2}{*}{ lneng } & -0.0920 & 0.152 & 0.0104 & 0.207 & -0.0772 & -0.0772 \\
\hline & $(-1.00)$ & $(0.83)$ & $(0.16)$ & (1.58) & $(-0.77)$ & $(-0.77)$ \\
\hline \multirow[t]{2}{*}{ lner } & $0.548 * * *$ & $0.249 * * *$ & $0.526 * * *$ & $0.211 * * *$ & $0.547 * * *$ & $0.547 * * *$ \\
\hline & (8.39) & (2.97) & (12.98) & $(4.20)$ & (8.22) & $(8.22)$ \\
\hline \multirow[t]{2}{*}{ _cons } & -0.831 & -0.492 & 0.308 & -0.834 & 2.364 & 2.364 \\
\hline & $(-0.41)$ & $(-0.41)$ & $(0.31)$ & $(-0.88)$ & (1.13) & (1.13) \\
\hline$N$ & 217 & 217 & 217 & 217 & 217 & 217 \\
\hline $\operatorname{adj} \cdot R^{2}$ & 0.831 & - & - & - & 0.828 & 0.828 \\
\hline
\end{tabular}

Notes: *** means $\mathrm{p}<0.01, * *$ means $\mathrm{p}<0.05, *$ means $\mathrm{p}<0.1$. 
Table 6. Panel model regression results after the 18th CPC National Congress.

\begin{tabular}{|c|c|c|c|c|c|c|}
\hline & (1) & (2) & (3) & (4) & (5) & (6) \\
\hline & OLS & RE ROBUST & GLS & MLE & IV-2SLS ROBUST & IV-GMM \\
\hline \multirow[t]{2}{*}{$\ln \left(\mathrm{Agy}^{2}\right)$} & $-8.091 * * *$ & $-4.071 * *$ & $-7.327 * * *$ & -2.483 & $-19.75 * * *$ & $-19.75^{* * *}$ \\
\hline & $(-3.16)$ & $(-2.51)$ & $(-3.55)$ & $(-1.24)$ & $(-3.59)$ & $(-3.59)$ \\
\hline \multirow[t]{2}{*}{$\ln \left(\mathrm{A}^{2} \mathrm{gy}\right)$} & $8.087^{* * *}$ & $4.570 * * *$ & $7.771 * * *$ & $3.308^{* *}$ & $20.18^{* * *}$ & $20.18^{* * *}$ \\
\hline & $(3.53)$ & $(3.26)$ & $(4.12)$ & (2.14) & (3.95) & (3.95) \\
\hline \multirow[t]{2}{*}{ lnmanu } & $1.875^{* * *}$ & $2.500 * * *$ & $2.153^{* * *}$ & $2.653^{* * *}$ & $1.708^{* * *}$ & $1.708^{* * *}$ \\
\hline & $(10.24)$ & $(4.23)$ & $(14.37)$ & $(8.52)$ & (7.62) & (7.62) \\
\hline \multirow[t]{2}{*}{ lnopen } & -0.0389 & -0.101 & 0.0770 & $-0.324 * *$ & -0.0159 & -0.0159 \\
\hline & $(-0.40)$ & $(-0.75)$ & (1.13) & $(-2.24)$ & $(-0.15)$ & $(-0.15)$ \\
\hline \multirow[t]{2}{*}{$\operatorname{lnrd}$} & -0.0400 & 0.0758 & -0.00110 & 0.126 & 0.0233 & 0.0233 \\
\hline & $(-0.60)$ & $(0.73)$ & $(-0.03)$ & $(0.90)$ & $(0.35)$ & $(0.35)$ \\
\hline \multirow[t]{2}{*}{ lnur } & $0.978 * *$ & 0.190 & $0.671 * *$ & -0.336 & $1.820 * * *$ & $1.820 * * *$ \\
\hline & $(2.21)$ & $(0.29)$ & $(2.02)$ & $(-0.41)$ & (3.19) & (3.19) \\
\hline \multirow[t]{2}{*}{$\operatorname{lnpd}$} & -0.0425 & $0.236^{*}$ & -0.0332 & $0.621 * * *$ & 0.00812 & 0.00812 \\
\hline & $(-0.58)$ & $(1.78)$ & $(-0.57)$ & $(2.73)$ & $(0.10)$ & $(0.10)$ \\
\hline \multirow[t]{2}{*}{ lneng } & $0.354 *$ & $1.559 * * *$ & $0.545^{* * *}$ & $2.423^{* * *}$ & $0.438^{*}$ & $0.438^{*}$ \\
\hline & (1.93) & (4.15) & $(3.20)$ & $(5.47)$ & (1.79) & (1.79) \\
\hline \multirow[t]{2}{*}{ lner } & $0.370^{* * *}$ & -0.241 & $0.427 * * *$ & $-0.354 * * *$ & $0.360 * *$ & $0.360 * *$ \\
\hline & (3.07) & $(-1.63)$ & $(4.22)$ & $(-3.24)$ & $(2.21)$ & $(2.21)$ \\
\hline \multirow{2}{*}{ _cons } & -0.00222 & -1.809 & 1.254 & -0.924 & 1.158 & 1.158 \\
\hline & $(-0.00)$ & $(-1.16)$ & (1.36) & $(-0.57)$ & $(0.87)$ & $(0.87)$ \\
\hline$N$ & 155 & 155 & 155 & 155 & 155 & 155 \\
\hline $\operatorname{adj} \cdot R^{2}$ & 0.595 & - & - & - & 0.517 & 0.517 \\
\hline
\end{tabular}

Notes: *** means $\mathrm{p}<0.01, * *$ means $\mathrm{p}<0.05$, * means $\mathrm{p}<0.1$.

We can see in Table 5 that the EKC hypothesis is not significant before re-selection of central government and anti-corruption reduces the inflexion point of economic growth in a province; after the $18^{\text {th }}$ CPC National Congress, we can see in Table 6 that the coefficient of the core variable increased significantly. There is an inverted $\mathrm{N}$ EKC in different provinces, and anti-corruption significantly reduces the inflexion point of economic growth. With the strengthening of anti-corruption after the $18^{\text {th }}$ CPC National Congress, the role of anti-corruption, economic growth, and environmental pollution may start to enter a virtuous circle. After a period of $U$ fluctuations, environmental pollution began showing a downward trend and the environmental pollution situation was significantly improved. In addition, some invisible economics has been restrained. Under the same economic volume, the proportion of invisible economy is getting smaller. The production cost of polluting enterprises who enjoy the protection of the local government through 'rent-seeking' and other forms has increased, the profit level has decreased, and the economic system has become more reasonable and healthier. At a lower level of economic growth, environmental pollution began to show a downward trend, which also means that the number of provinces affected by different economic conditions increases, and the level of environmental pollution in each province decreased obviously.

\section{Robust Test}

\section{Replace Pollutant Index}

Industrial $\mathrm{SO}_{2}$ emission per capital cannot represent the overall environmental pollution level of a province. Consequently, EKC in a province and among provinces is tested using the sum of capital industrial solid waste and per capital chemical oxygen demand in industrial wastewater in this paper and the results are consistent 
Table 7. Regression results of panel model robustness test.

\begin{tabular}{|c|c|c|c|c|c|c|}
\hline & (1) & (2) & (3) & (4) & (5) & (6) \\
\hline & OLS & RE ROBUST & GLS & MLE & IV-2SLS ROBUST & IV-GMM \\
\hline \multirow[t]{2}{*}{$\ln \left(\mathrm{Agy}^{2}\right)$} & $-2.738^{* * *}$ & $-4.112 * * *$ & $-2.655^{* * *}$ & $-4.656^{* * *}$ & $-18.16^{* * *}$ & $-18.16^{* * *}$ \\
\hline & $(-2.85)$ & $(-3.23)$ & $(-3.10)$ & $(-5.70)$ & $(-3.03)$ & $(-3.03)$ \\
\hline \multirow[t]{2}{*}{$\ln \left(\mathrm{A}^{2} \mathrm{gy}\right)$} & 0.505 & $2.366^{* * *}$ & $1.280^{* *}$ & $2.923 * * *$ & $14.26^{* * *}$ & $14.26^{* * *}$ \\
\hline & $(0.67)$ & $(4.49)$ & (2.19) & $(4.68)$ & $(2.68)$ & $(2.68)$ \\
\hline \multirow[t]{2}{*}{ lnmanu } & $1.973 * * *$ & $1.810^{* * *}$ & $2.097 * * *$ & $1.490^{* * *}$ & $2.360 * * *$ & $2.360^{* * *}$ \\
\hline & $(21.38)$ & $(4.22)$ & $(21.95)$ & $(8.38)$ & $(10.51)$ & $(10.51)$ \\
\hline \multirow[t]{2}{*}{ lnopen } & $-0.0891 * *$ & $-0.145^{*}$ & -0.0407 & $-0.163 * * *$ & 0.106 & 0.106 \\
\hline & $(-2.02)$ & $(-1.75)$ & $(-1.18)$ & $(-2.62)$ & (1.09) & (1.09) \\
\hline \multirow[t]{2}{*}{$\operatorname{lnrd}$} & -0.00485 & -0.0883 & 0.00267 & $-0.158 * *$ & $0.137 *$ & $0.137^{*}$ \\
\hline & $(-0.15)$ & $(-1.04)$ & $(0.11)$ & $(-2.10)$ & (1.94) & (1.94) \\
\hline \multirow[t]{2}{*}{$\operatorname{lnur}$} & $1.053 * * *$ & 0.502 & $0.682 * * *$ & 0.122 & $0.728 * * *$ & $0.728 * * *$ \\
\hline & $(6.01)$ & $(1.50)$ & $(4.70)$ & $(0.33)$ & $(2.75)$ & $(2.75)$ \\
\hline \multirow[t]{2}{*}{$\operatorname{lnpd}$} & -0.0522 & $0.207^{*}$ & -0.0341 & $0.337 * * *$ & 0.109 & 0.109 \\
\hline & $(-1.51)$ & $(1.82)$ & $(-1.14)$ & $(3.46)$ & $(1.36)$ & $(1.36)$ \\
\hline \multirow[t]{2}{*}{ lneng } & $0.289 * * *$ & $1.001 * * *$ & $0.438 * * *$ & $1.154 * * *$ & $0.759 * * *$ & $0.759 * * *$ \\
\hline & $(3.26)$ & $(3.80)$ & (5.13) & $(7.66)$ & $(3.28)$ & $(3.28)$ \\
\hline \multirow[t]{2}{*}{ lner } & $0.375 * * *$ & -0.0937 & $0.374 * * *$ & $-0.194 * * *$ & $0.581 * * *$ & $0.581 * * *$ \\
\hline & $(6.16)$ & $(-0.76)$ & (7.12) & $(-3.06)$ & $(5.28)$ & $(5.28)$ \\
\hline \multirow[t]{2}{*}{ _cons } & -0.730 & $-3.958 * * *$ & -0.334 & $-5.227 * * *$ & 1.420 & 1.420 \\
\hline & $(-1.34)$ & $(-3.27)$ & $(-0.73)$ & $(-6.12)$ & $(1.22)$ & $(1.22)$ \\
\hline$N$ & 372 & 372 & 372 & 372 & 372 & 372 \\
\hline $\operatorname{adj} \cdot R^{2}$ & 0.718 & - & - & - & 0.460 & 0.460 \\
\hline
\end{tabular}

Notes: $* * *$ means $\mathrm{p}<0.01, * *$ means $\mathrm{p}<0.05, *$ means $\mathrm{p}<0.1$.

with the previous studies. The results are shown in columns (2), (5) and (8) in Table 4.

\section{Change Anti-Corruption Index}

Taking the change of the central government as an alternative variable of anti-corruption, as is stated above, all the regression results are the same, which proves that the conclusion of this paper is robust. The results of EKC in a province are shown in Table 7, and the results of EKC hypothesis among provinces are shown in columns (3), (6) and (9) in Table 4.

\section{Conclusions}

Taking China as a case study, based on the balanced panel data of 31 provinces and cities from 2006 to 2017, this study puts anti-corruption factors into the framework of the new EKC model. Moreover, this study uses a panel model and spatial Durbin model to empirically test the impact of anti-corruption on the relationship between economic growth and environment and its spillover effect. The results are as follows:

1) China's EKC presents an inverted $N$ shape; that is, economic growth has a critical point for increasing and reducing emissions. When the level of economic growth exceeds a certain threshold, economic growth can exhibit a significant reduction effect on pollution emissions. Simultaneously, anti-corruption within the region will impact the EKC outside the region, but the spillover effect is lower than the internal effect.

2) Anti-corruption can affect the turning point and shape of the EKC to a certain extent by optimising economic growth and curbing environmental pollution. This shows that the energy-saving and emissionreduction mechanism of economic growth stems not only from the positive externalities, such as economic growth's scale effect, structural effect and technological 
effect, but also from anti-corruption, which is an important factor.

3) A time difference exists in China's EKC. After the $18^{\text {th }}$ National Congress of the Communist Party of China, the EKC showed a significant inverted $\mathrm{N}$ shape, and anti-corruption significantly reduced the inflexion point of the relationship between economic growth and environmental pollution. This shows that strong anticorruption policies play an important role in promoting the formation of China's EKC.

Based on the above research conclusions, this paper proposes three corresponding suggestions: Firstly, anti-corruption has an important impact on the shape and inflexion point of the EKC; therefore, scholars should not ignore the effect of this condition when conducting research on EKC. Secondly, the corruption must be strictly contained, and joint anti-corruption power among regions must be enhanced. Instead of a single action, we should strictly control the party's anti-corruption construction from daily work. In view of the result that the inflexion point of economic growth was reduced after the 18th National Congress, we should hold the line to implement the anti-corruption policy. On the one hand, a political environment with clean and healthy atmosphere must be created. On the other hand, a crackdown on environmental corruption is required, and environmental quality must be improved. Thirdly, policymakers should pay attention to strengthen environmental regulations, upgrade and explore green technology, promote industrial transformation, and realise that anti-corruption is not the only effective means to solve the problem of environmental pollution.

\section{Acknowledgements}

The authors are grateful to all peer reviewers for their reviews and comments. This paper is supported by The National Social Science Foundation of China (17ZDA081).

\section{Conflict of Interest}

The authors declare no conflict of interest.

\section{References}

1. BAO Q., PENG S.J., YANG X.X. Is there an environmental Kuznets inverted U-shaped curve?: Empirical research based on six types of pollution indicators. Shanghai Journal of Economics, 12, 3, 2005 [In Chinese].

2. WANG X.B., WANG L.Y. Combating Corruption and Promoting Economic Growth. Comparative Economic \& Social Systems, 2, 61, 2016 [In Chinese].

3. LIU S., YANG D.H. Can Anti-corruption Restrain Environmental Pollution? : Based on the Analysis of the Interaction between Anti-corruption and Environmental
Regulation. Contemporary Economy \& Management, 42 (3), 27, 2020 [In Chinese].

4. ZHOU M.L., WANG B., CHEN Z. Has the anti-corruption campaign decreased air pollution in China? [J]. Energy Economics, 91, 2020.

5. RAMÓN L., MITRA A.S. Corruption, pollution, and the Kuznets environment curve. Journal of Environmental Economics \& Management, 40 (2), 137, 2000.

6. COLE M.A. Corruption, income and the environment: an empirical analysis. Ecological Economics, 62 (3-4), 637, 2007.

7. LEITAO A. Corruption and the environmental kuznets curve: empirical evidence for sulfur. Ecological Economics, 69 (11), 2191, 2010.

8. FREDRIKSSON P.G., SVENSSON J. Political instability, corruption and policy formation: the case of environmental policy. Journal of Public Economics, 87 (7), 1383, 2003.

9. JIE H., PAUL M., QUENTIN W. Corruption, Inequality, and Environmental Regulation. Cahiers De Recherche, 2007.

10. LIANG P.H., GAO N. Personnel change, legal environment and local environmental pollution. Management World, 6, 65, 2014 [In Chinese].

11. YU C.L., GAO H.J. The Effect of Environmental Regulation on Environmental Pollution in China: Based on the Hidden Economy Perspective. China Industrial Economics, 7, 21, 2015 [In Chinese].

12. DAMANIA R., FREDRIKSSON P.G., LIST J.A. Trade liberalization, corruption, and environmental policy formation: theory and evidence. Journal of Environmental Economics \& Management, 46 (3), 490, 2003.

13. LI Z.H., LIU H.H. Are There Threshold Effects of FDI on Environment?: Evidence from 220 Cites in China. Finance \&Trade Economics, 9, 101, 2012 [In Chinese].

14. SHI Q. Foreign Direct Investment, Environmental Regulation and Environment Pollution: From the Perspective of Government Honest Degree. Finance \& Trade Economics, 1, 95, 2013 [In Chinese].

15. BISWAS A.K., FARZANEGAN M.R., THUM M. Pollution, shadow-economy and corruption: theory and evidence. Ecological Economics, 75, 114, 2012.

16. YU C.L. How Does Corruption Affect Environmental Pollution in China:Based on the Informal Economy Perspective. Chinese Journal of Management Science, 27 (5), 140, 2019 [In Chinese].

17. NIE H.H., LI C. Entry Regulation, Corruption and AntiCorruption Policy. The Journal of World Economy, 40 (8), 103, 2017 [In Chinese].

18. WANG F., YAO S.J., QU G.J. Sustainable and Steady Economic Growth under Anti-corruption in China. Economic Research Journal, 53 (1), 65, 2018 [In Chinese].

19. DANG L., YANG R.L., YANG J.D. Anti-Corruption and Firms'Innovations: An Explanation from Political Connections. China Industrial Economics, 7, 146, 2015 [In Chinese].

20. ZHONG Q.L., LU Z.F., YUAN C. Anti-corruption, Firm Performance and Channel Effects: Based on Anticorruption Campaign of 18th CPC National Congress. Journal of Financial Research, 9, 161, 2016 [In Chinese].

21. WANG M.B., KONG D.M. Anti-corruption and Chinese Corporate Governance: A Quasi-Natural Experiment. Journal of Financial Research, 8, 159, 2016 [In Chinese].

22. WANG X.B., HUANG L.X., DONG Y.J. The Investment Effect of Anti-corruption: Evidence from Regional and Enterprises Dimensions. Journal of Financial Research, 9, 67, 2017 [In Chinese]. 
23. YAN Y.Y., QIAO S.J. Micro Effect Evaluation of Anticorruption: Fromthe Perspective of Executive Incentive. Economic Perspectives, 2, 36, 2018 [In Chinese].

24. ZHANG H., LI Z.F., DENG B.J. Community of Interests, Anti-corruptionand Housing Prices: Evidence from China. Journal of Management Sciences in China, 21 (8), 21, 2018 [In Chinese].

25. WANG G.M., WANG Y.D., YANG X. An Empirical Research on the Effects of Environmental Regulation on Environment Kuznets Curve. Soft Science, 31 (12), 78, 2017 [In Chinese].

26. JIN S.W., WU J. Corruption, Economic Growth and the Environmental Curve: Evidence from the Data of Sulfur Dioxide Emissions. Economic Theory and Business Management, 6, 28, 2014 [In Chinese].

27. WAGNER M. The carbon Kuznets curve: a cloudy picture emitted by bad econometrics?. Resource \& Energy Economics, 30 (3), 388, 2008.

28. BRADFORD D.F., FENDER R.A., SHORE S.H., MARTIN W. The environmental Kuznets curve: exploring a fresh specification. The B.E. Journal of Economic Analysis \& Policy, 4, 2005.
29. OUYANG Y.Y., HUANG X.F., ZHONG L.M. The Impact of Outward Foreign Direct Investment on Environmental Pollution in Home Country: Local and Spatial Spillover Effects. China Industrial Economics, 383 (2), 126, 2020 [In Chinese].

30. WANG J.Z., GAO M.H. Anti-corruption, Entrepreneurial Competencies and Enterprise Innovation. Business Management Journal, 6 (466), 38, 2017 [In Chinese].

31. ELHORST J.P. Matlab Software for Spatial Panels[J]. International Regional Science Review, 37 (3), 389, 2014.

32. DONG Z.Q., WEI X.H., TANG C.Q. System Soft Environment and Economic Development: Empirical Study on Business Environment of 30 Big Cities. Management World, 4, 9-20, 2012 [In Chinese].

33. TIAN B.F., CHEN Z.R. Spatial Spillover of FDI on Entrepreneurship in China. China Industrial Economics, 8, 40, 2016 [In Chinese].

34. WAN G.H., WU Y.P. Law Institutions, Wage Incentives and Corruption Reduction: The Case of China. China Economic Quarterly, 11 (3), 997, 2012 [In Chinese]. 